Revista Internacional de Apoyo a la Inclusión, Logopedia, Sociedad y Multiculturalidad.

Volumen 6, Número 1, enero 2020, ISSN: 2387-0907. DOI: https://doi.org/10.17561/riai.v6.n1.09

\title{
Maná del cielo: ¿fantasía religiosa para los mayores, o resiliencia en las dificultades de la vida?
}

Manna of heaven: Religious fantasy for the elderly, or resilience in the difficulties of life?

\author{
Maria Suênia de Medeiros Gomes \\ Universidade Católica de Pernambuco (Brasil) \\ sueniaster@gmail.com \\ Luiz Alencar Libório \\ Universidade Católica de Pernambuco (Brasil) \\ ppgcrunicap@gmail.com
}

Fecha recepción: 03/11/2019

Páginas 98-108

Fecha aceptación: 25/12/2019

\section{Resumen.}

El nuevo paradigma de ancianos en Brasil nos hace reflexionar sobre la búsqueda por proyectos de vida, el compromiso con la salida y con la dimensión espiritual. Delante de este nuevo escenario, se objetivó investigar si la religión puede ser un recurso de resiliencia para los que buscan un envejecimiento saludable. Se realizó un abordaje exploratorio, fundamentado en la teoría de Viktor Frankl (2008), ícono de la resiliencia por la superación en el período en el cual fue prisionero en Auschwitz y consecuentemente responder al sufrimiento con dignidad. También se abarcará a Jung, por sus pesquisas con experiencias religiosas, además de otros autores que contribuyeron para el enriquecimiento de la temática presentada. El fenómeno de la muerte encontrado en Kübler-Ross (2017), la exposición sobre los escenarios de las iglesias en Brasil impregnados de muertes, asaltos y el uso abusivo del móvil, cuyo hábito se define como nomofobia, fueron analizados. Ante todo, lo expuesto, uno cree que cuanto más viejo, más resiliente la persona se vuelve, y el "maná" estimula a llegar a la tierra prometida.

Palabras clave: envejecimiento; muerte; religión; vida; resiliencia

\begin{abstract}
.
The novel paradigm of the elderly in Brazil reflects the search for life projects, the commitment with health, and the spiritual dimension. Facing this new scenery, the main goal was to investigate whether religion may or not be a resilience resource for those who seek after a healthy aging process. An exploratory approach was made, based on Viktor Frankl's theory, an icon of resilience by overcoming his imprisonment in Auschwitz and, as a consequence, responding to such painfulness with dignity, including Jung as well, owing to his researches on religious experiences, besides other authors who have contributed to the enrichment of the present theme. The
\end{abstract}


phenomenon of death found in Kübler-Ross (2017), and the exhibition concerning sceneries of churches in Brazil permeated with deaths, robberies, excessive use of cellular telephones whose habit is defined as nomophobia, were analyzed. Hence, it is believed that the older, the more resilient a person becomes, and the "manna" stimulates the arrival at the Promised Land.

Keywords: aging; death; religion; life; resilience

\section{1.-Introducción.}

El proceso de modernización de la sociedad puede haber generado en una misma familia, brasileños que tienen bisabuelos paternos africanos y que hayan desarrollado la función de sacerdotes druidas; abuelos maternos italianos con fe cristiana, cuyos hijos optaron por vivir en China, creer en el Budismo y casarse con personas que no tienen vínculo con ninguna religión. Vivimos en una sociedad multiétnica, expuestos a lo imprevisible, inundaciones, muertes, y asaltos dentro de la propia iglesia, desconsiderando este espacio como lugar sagrado, todo esto afecta al escenario socio-político-religioso-económico-ecológico del mundo; esas inquietudes generan ansiedad, consumismo exacerbado y enfermedades epidemiológicas.

¿Estamos preparados para saber lidiar con el pluralismo religioso, el flujo de refugiados y con los avances tecnológicos? Visto que la sicología ha reconocido, en estos avances, que algunas personas desarrollan una dependencia patológica de la WEB, la nomofobia; hace que ella se aísle del mundo real. Sin embargo, son los propios avances tecnológicos y científicos que incentivan a caminar para adelante, creer en la posibilidad de vivir más, mientras que las religiones luchan por la integración de los conceptos mentales y corporales con el espíritu eterno.

Desde el punto de vista de lo multicultural, Brasil enfrenta un sorprendente proceso de envejecimiento que se transforma en un desafío para las políticas públicas actuales y para todos los individuos que tienen como objetivo alcanzar los 120 años. De este modo, en ese medio social de vulnerabilidad, la resiliencia, viene a ser una herramienta que tiene que desarrollarse, pues enfrentar la muerte, soportar dolores y pérdidas, desarrollar fuerza interior para persistir frente a los obstáculos y mantener la esperanza de días mejores, todo exige esfuerzo y aprendizaje. Pero, ¿será que la fe inspira a los ancianos a buscar la Tierra prometida?

\section{2.-Desenvolvimento.}

Allí viene la fuerza, allí viene la magia, que incendia el cuerpo de alegría. (Brant., Nascimento, 1976)

Se observa el papel de los artistas culturales en la resiliencia. Todos tienen una canción, una película, un libro que ha ayudado a ultrapasar obstáculos, que ha fortalecido y ha encorajado a seguir adelante. Todos ya han tenido un "maná", algo de lo que se han nutrido físicamente, emocionalmente o espiritualmente, que han 
sostenido, han apoyado, se han guiado cuando no sabían qué hacer y se sentían impotentes y sin dirección, como ocurrió en las historia bíblicas: [...] un "maná" que ni tú, ni tus padres conocían, para mostrarte que el hombre no vive apenas de pan [...]" (Varios, 2004, p174)

El diálogo con el Divino, proporciona un encuentro profundo con una fuerza superior que te consuela, ayuda a proseguir, te hace recordar las oraciones que llevamos dentro, y los ejemplos de los Santos que cargan con la memoria, lo que nos remite al concepto de espiritualidad inconsciente de Dios, ese relacionamiento transcendente que atraviesa todas las experiencias existenciales que uno lleva, y que nutre, genera confianza, y nos revitaliza para que continuemos caminando. (Frankl, 2007, p.63).

Colocarse espiritualmente de una forma valerosa delante del sufrimiento es aprender a que uno no se deje dominar por la desesperación, aceptar que la vida puede ser injusta, a pesar de todas las actitudes éticas que se hayan demostrados con los demás. Encarar las situaciones difíciles como lección y dar un nuevo significado a las experiencias vividas, demostrando auto-responsabilidad, pues "[...] si hay un propósito en la vida, debe de haberlo también en el dolor y en la muerte [...]" (Frankl, 2008. p.97), por lo tanto, se hace necesario saber responder a la vida de manera virtuosa, encontrar dentro de sí, un lugar de esperanza, donde la imaginación nos estimule a crear un futuro feliz.

El fenómeno religioso fue observado por Jung (2003), acoplándolo a percepciones sicológicas. Posteriormente, él designó a la religión como: "La actitud particular de una consciencia transformada por la experiencia del numinoso". En este sentido, Jung admite en la estructura profunda de la mente humana una potencialidad natural que ejerce una función transcendente e impulsa al ser humano a buscar a Dios, y relacionarse con él mediante la religión. (Jung, 2012, p.21). Entonces cuando surgen aquellos obstáculos insoportables, que se juzgan insuperables, los mismos se pueden incorporar como si fueran un enfoque de nuevas reflexiones y enseñanzas (Jung, 2012, p.27). Tales experiencias religiosas fueron analizadas conforme el siguiente registro, hecho por Boechat (2014).

Se sabe que los ancestrales de Jung por parte materna siempre tuvieron gran intimidad con las manifestaciones espirituales. Samuel Preiswerk, su abuelo materno, tenía visiones y era mediante los muertos que interferían en las preparaciones de sus sermones como pastor. Su prima materna realizaba secciones mediúnicas, que, como se sabe, fueron estudiadas por Jung para la formulación de su tesis de doctorado en medicina. (Boechat, 2014, p.116)

Sin embargo, Jung (2012), ve esos fenómenos mediúnicos como proyecciones de la mente humana, según análisis de Lachman (2012). Jung también ayudó a varias personas mediante sus pesquisas, para que ellas pudiesen comprender las manifestaciones religiosas que sentían como siendo pertinente al carácter humano, y ese sentimiento de perteneciente contribuyó para que aceptaran sus dones y aprendieran a desarrollarlos. 
2.1.-De dónde viene esa cosa tan mía, que me calienta y me hace cariño (Brant., Nascimento,1976)

Edith Eva Eger, 91 años, judía, y también sobrevivió al campo de concentración de Auschwitz. Tuvo la oportunidad de encontrarse personalmente con Viktor Frankl (2008) y conversar sobre los recursos que usaron para ultrapasar los peores momentos. Frankl (2008) le contó que construyó un santuario interior que lo inspiraba a tener esperanza y lo ayudaba a imaginarse como siendo un hombre libre, y con el propósito de llevar todo el conocimiento adquirido para beneficiar a otras personas. Eger le compartió que el día que su madre murió la forzaron a bailar para Josef Menguele (médico conocido como el ángel de la muerte) pues los soldados querían divertirse, y la misma relató que para soportar ese momento se transportó para Budapest, en la Ópera Hause y ambos escogieron visualizar la esperanza de días mejores (Eger, 2017, p.65).

Eger eligió no ser víctima de las injusticias, opresiones y humillaciones por las que pasó, se esforzó para curarse, incluso, luego de vivir en EE. UU, se sometió a análisis Junguiana de sus sueños, de secretos que había guardado en su interior y que no conseguía expresarlos. Según ella, lo opuesto de la depresión es la expresión. La misma escogió reaccionar, tener compasión, ser solidaria con los que sufren, y perdonar a los que la lastimaron, pues decidió no ser controlada por el pasado y sí florecer y mejorar su vida, optando por seguir adelante.

Es común pasar por fracasos y sentirse débil, avergonzado y cansado debido a las luchas vivenciadas. Toledo (2017) define resiliencia como siendo una postura emocional y espiritual en el medio del caos. Según la autora, es como si uno estuviese pasando por un desierto árido, con escasez de recursos internos y externos, en el medio de todo ese sufrimiento que uno encuentre una nueva fuente de agua, que te ayuda a volver para las corrientes del río, y te ayuda a nadar para alcanzar tu misión, y te conecta con tus valores. Ella, ejemplifica a Jesús como ícono de resiliencia, pues que uno sea ridiculizado, despreciado, rechazado, y tenga que escuchar las voces de aquellos a quien él ayudó diciéndole crucifíquenlo, no debe de haber sido fácil. Además, él escogió mantener vínculo con el eterno y seguir conectado con la energía del amor. La autora enfatiza: "[...] no creas que los percances por los cuales pasaste te desautorizan de disfrutar los mejores escenarios que están por venir, pues ni la muerte es el fin cuando caminamos junto a Dios. " (Toledo, 2017, p.118).

La resiliencia es la fuerza que te ayuda a que no desanimes, a que te levantes delante de las caídas, a que no te abales frente a las luchas, es lo que uno escoge para capacitarse delante de una situación y no te achiques, ni veas el problema como si fuera insuperable. Es evitar irse para debajo de la cama o quedarse plasmado en las sábanas, al contrario, es obtener conocimiento para vencer. Los clásico infantiles también registran valores de resiliencia, como apunta Klein (2016), al analizar la historia de la cenicienta, caracterizando que ella aprendió a ser fuerte, pues según la autora, ella pasó por desprecio, burlas, humillaciones, pero no dejó que la derribaran, 
aguantó firme, no se desesperó, pero en cambio, buscó soluciones y tuvo paciencia para esperar que todo mejorase.

La culpabilidad, exceso de críticas, falta de límites, estar siempre cobrándose, la inflexibilidad, y el perfeccionismo exacerbados pueden detener los objetivos del individuo. Para que uno no se deje influenciar por esos comportamientos destructivos, Hay (2009) pesquisó a respecto del poder de las afirmaciones positivas, son mensajes que uno dice para sí propio(a), para tirar para arriba "[...] poseo una capacidad ilimitada para crear cosas buenas en mi vida" (Hay, 2009, p.12), " soy flexible y sigo la marea" [...]" (Hay, 2009, p.45),"[...] voy más allá de la manera humana limitada de pensar y al encuentro de la infinita mente divina para la cual todo es posible [...]" (Hay, 2009, p.63), "[...] cuento con la sabiduría y la orientación divina para que me protejan [...] (Hay, 2009, p74), y "[...] leo libros que enriquezcan mi alma y alimenten mi pensamiento [...] (Hay, 2009, p.93). Según la autora, ese diálogo de auto-apreciación y auto-valorización consigo propio(a), te ayudará a sentirte bien.

De esta manera, "Cuando te golpees fuerte y tu alma sangre, cuando ese mundo pesado te hiera, te aplaste... es la hora de volver a empezar. Recomienza a luchar. [...]" Bessa, 2018, p.74). En ese poema, el autor no estimula a imitar a los luchadores más admirados, a preguntarse cuál fue la lección que aprendimos cuando nos caímos, y a salir para animar a los que están tristes, Cuando erres, reaprende, gambetea, baila, y empuja hacia adelante.

Sandberg (2017) escribió sobre los refugiados en el mundo. Según ella, "[...] es una señal de fuerza reconocer que uno no tiene habilidades necesarias para hacer algo y pedir ayuda, querer mejorar no es una señal de debilidad [...]" (Sandberg, 2017, p. 125). O sea, los refugiados son personas que sienten opresión, soledad, que tuvieron rupturas de los vínculos familiares, y de muchos amigos que tuvieron que abandonar para arribar de su tierra de origen para buscar alimento, agua, paz, cosas que a veces, las personas tienen en su vida cotidiana y no saben valorizarlas. Esos individuos muchas veces llegan a países que ni siquiera conocen el idioma, pero entran en templos religiosos que consideran un refugio santo, una forma de entrar en conexión con la fuerza de Dios para consolar y aliviar sus aflicciones, y que puedan ayudarlos a confortar los dolores, así rezan, oran y hacen oraciones (Sanderg, 2017, p.98).

Bijos (2013) relató sobre los disgustos encontrados en la emigración. Conforme la autora en foco, es necesario esforzarse y desarrollar la fuerza de voluntad para superar el rechazo, el prejuicio, la xenofobia. Entretanto, ella también refuerza, de forma paradoxal, que todo ese aprendizaje se trasformará en una experiencia interior de fuerza y coraje (Bijos, 2013, p. 276).

De esta manera, la adversidad resulta una buena escuela, de una compleja realidad en la que los que emigran están inseridos, y nuevas dimensiones sociales, políticas, económicas, culturales, y religiosas probablemente serán exploradas. Según Bijos (2013), ocurrirá en los refugiados un proceso de reconfiguración de identidad que 
podrá interferir en la manera de percibir el mundo a su alrededor, y en la comprensión de las instituciones religiosas.

El brasileño que emigra para Japón, por ejemplo, se va a encontrar con una comunidad con valores budistas, muchas veces distintas de sus padrones religiosos cristianos en Brasil. ¿Cómo interpretar el sentido que uno pertenece a una determinada denominación religiosa, si el individuo no podrá recibir apoyo de servicios religiosos en aquel país? (Bijos, 2013, p.294).

Al respecto, se hace necesario que se construyan espacios para debatir sobre el diálogo inter-religioso, sobre los conflictos que se hacen presentes a través de los cambios culturales. También se observa que "en contrapartida a todas las dificultades en el exterior, el emigrante establece un vínculo con la religiosidad, a fin de sostenerse psicológicamente; y reestablezca su harmonía interior" (Bijos, 2013, p. 306)

La resiliencia es un asunto que está en la pauta de varios países. El manual de resiliencia 2.0 para técnicos de cooperación y responsabilidades sociales (Nederland, 2013), alerta sobre las vulnerabilidades en el mundo, por no estar preparados para saber lidiar con los cambios climáticos, choques interculturales, hacinamiento de personas y desastres ecológicos. Según los investigadores, el diálogo transfronterizo precisa aprender sobre resiliencia para establecer estrategias. La resiliencia es definida por ellos como siendo la "capacidad de adaptación de un sistema, comunidad, sociedad potencialmente expuesta a amenazas, resistiendo a cambios con la finalidad de mantener un nivel aceptable de funcionamiento y estructura. Refleja el grado en el cual el sistema social es capaz de auto-organizarse para aumentar su capacidad de aprender con los desastres que ocurrieron, como objetivo de una mejor protección futura y perfeccionar las medidas de reducción de riesgo" (2013, p.10). Los países que pasaron por catástrofes, como Japón, ya comprendieron que solo una persona es importante para hacer algo, quien ya enfrentó la furia de las fuerzas de la naturaleza y se hirió, percibió que en esos momentos uno puede contar con la ayuda mutua de las personas (Taniguchi, 2019, p.07). Esa fuerza de solidaridad las religiones también la enseñan.

Aprender con los acontecimientos infelices, también fue objeto de estudio de Cyrulnik (2012, p.43). Él apunta que "[...] empezar mal en la vida no determina que tu vida tenga que ser desgraciada [...]". Según el autor, la resiliencia puede ser definida por la habilidad que una persona tiene en buscar momentos felices, a pesar de todas las heridas que sangran en el alma. O sea, transmudar el dolor, darse un aprendizaje, un sentido. Por lo tanto, la hija de un alcohólico que sufrió con la ausencia del padre, buscará como pareja, un hombre que le ponga atención, y que se vuelva una persona solidaria y altruista con el dolor del prójimo, pues lleva en el alma el abandono. Es diferente de un niño que fue maltratado por el padre que era agresivo y violento; repite el modelo, cuando se convierta en adulto. Por ello, podrá propagar lo que sufrió, pegándoles también a las mujeres, dicho de otro modo, sigue preso en su dolor que no reinterpretó. 
Otro autor que también estudió sobre la resiliencia fue Tim Guénard. El mismo relató que en su infancia, cuando tenía tres años, su madre lo ató a un poste de electricidad y lo abandonó. A los cinco años, su padre que era alcohólico, le pegó tanto que lo desfiguró. Lo atendieron en un hospital y nadie fue a visitarlo, entonces creó un muñequito para fingir que alguien lo iba a ver, y por eso no se sentía solito. Después fue a un orfanato, donde pasó por muchas humillaciones, donde entró en contacto con la prostitución y las drogas. En su juventud, se convirtió al catolicismo como resultado de las conversaciones con un cura, cuya bondad lo dejó impresionado. Hoy en día, es casado, tiene cuatro hijos, y va a las prisiones en los hospitales psiquiátricos para hablar sobre el poder del amor de Dios (Guèrnad, 2016). Este relato enfatiza la definición de Fromm (1987, p. 60), que según él "[...] el amor es una actividad creadora, implica tener cuidados, significa traer la vida, aumentar la vida. Es un proceso, auto-renovador y auto-creciente. [...]"

Observa en los estudios de resiliencia, que debido a las enfermedades, algunos ancianos se sienten vulnerables. Sin embargo, Bernet (2018, p.197) cita en su libro, el investigador de la resiliencia George Bonanno, un innovador en ese asunto, y hace la siguiente afirmación: "[...] las personas mayores consiguen lidiar mejor con las dificultades [...]". Es decir, la resiliencia aumenta con la edad, podemos recurrir a más experiencias, mejorar la capacidad de adaptación, y comprender mejor lo que uno no puede cambiar.

La campaña, viejo es lindo, lanzada por Miriam Goldenberg, fue realizada con una convocatoria, en la cual la autora, invita a las persona a que cambien sus arcaicas representaciones, pues, "[...] el mercado sigue reproduciendo las imágenes de los viejos del siglo pasado y no ve a los "nuevos viejos", que tienen proyectos de vida, salud, amor, felicidad, libertad y belleza [...]", (Goldenberg, 2016, p.8).

Gusmão (2001, p. 136) aborda entre otros temas, sobre la importancia del "[...] compromiso consigo mismo y con el prójimo [...]" Esto es, hay que evitar la autonegligencia y desarrollar coraje para aceptar la mortalidad, enfrentando el miedo de morirse, así como el miedo de salir a buscar aquello que le trae esperanza a uno.

2.2.-Prepare su corazón para lo que le voy a decir, yo vengo de allá del semiárido, yo vengo de allá del semiárido y puedo no gustarle, aprendí a decir no, ver la muerte sin llorar. (Vendré.,Barros, 1996)

Existe el prejuicio en relación a la muerte, y hasta los que la enfrentan cotidianamente, buscan su negación. La represión de los sentimientos es muy común, principalmente en los hospitales, como destacó Kübler-Ross (2017), investigadora, la cual observó que la mayoría de los profesionales no querían oír que los pacientes hablaran de la muerte. La autora trabajó para humanizar la muerte, y llevarles dignidad a sus pacientes en la medida que los escuchaba expresando sus sentimientos, y concluyó, tras entrevistar un elevado número de pacientes que "[...] la muerte no existe, el ser humano poseía alma y espíritu, tenía una razón más elevada para la vida [...]" (Küler-ross, 2017, p. 213). 
Philippe (2014) destaca la exploración comercial que ocurre cuando algunas personas pierden la vida, mientras sienten el dolor de la pérdida de los entes queridos, el comercio los presiona queriendo ganancia con la venta de cajones y de lugares en los cementerios. El autor enfatiza también que existe "[...] una relación estrecha entre buen vivir y buen morir [...]" (Philippe, 2014, P. 398)

Respetar la muerte también ha sido una lucha librada por Arantes (2016), pues según ella, la sociedad a toda hora se prepara para vencer, para ganar, olvidándose que perder también forma parte de la vida. Jonquiéres (2017), al escribir a respecto de los ejercicios espirituales de Santo Ignacio de Loyola, sobre la temática de la muerte, destacó que esa meditación es importante para que las personas observen su propio egoísmo y el apego a las ilusiones del mundo transitorio. Desde el punto de vista de Boff (2012) sobre la muerte, es de contemplarla como una meta alcanzada. Santana (2011) describió una homilía proferida por Don Hélder Cámara, realizada en la Catedral de Olinda, en Recife, en una misa del séptimo día, por el fallecimiento de un amigo, en el cual, aparte de hablar sobre el sentimiento de esperanza para aquellos que creen en la eternidad, Don Hélder profirió: " Padre Celestial, gracias por la coherencia perfecta entre lo que él predicó y lo que él vivió [...]" Santana, 2011, p. 198) haciéndonos reflexionar que la honestidad de practicar lo que uno dice da sentido a la vida.

Reflexionando a respecto de la esperanza, Marshall (2009, p.132) formula la siguiente consideración: "[...] el paso más lento hacia la cume de la montaña, hacia el amanecer, hacia la esperanza, es más intenso que la más violenta de las tempestades [...] .Él considera que la esperanza ayuda a vencer la desesperación, a aceptar la realidad, por lo tanto, profundiza el conocimiento a respecto de ese tema y se constituye en un aprendizaje sobre el arte de ser fuerte, pues la esperanza es la compañera de los oprimidos, pero también es hija del esfuerzo. Por eso, aguantar firme la tempestad es aceptar los momentos difíciles, como la muerte de personas queridas. Rodrigues (2016) reafirma la clara percepción de que la esperanza es compañera de la creatividad, lo que implica un cambio positivo.

2.3.-Es mi fuerza, es mi energía que viene desde lejos para hacernos compañía (Brant., Nascimento, 1976)

Se observa que las religiones están relacionadas a las necesidades humanas, "Toda religión se presenta así como un sistema constituido por una gran reflexión sobre los problemas fundamentales que el hombre debe enfrentar: la vida, la muerte, el amor, el mal y el bien [...]" (Meslin, 2014, p.15). Sin embargo algunos contextos religiosos están intentando controlar y comprar la gracia divina a través del dinero, lo que lleva al hecho de la reclamación de algunos fieles a respecto de la falta de ética.

Actualmente, se verifica en la sociedad de consumismo, que los fieles van a las iglesias para mostrar sus modernos teléfonos celulares, para parecer lo que no son. En esta comunicación de la apariencia, el desorden prevalece, pues todo se tiene que filmar para que se pueda mostrar, y los momentos de experiencias significativas 
y oraciones no se vivencian, se muestran, molestando a las personas que se encuentran alrededor y necesitan el silencio para meditar.

Las iglesias están llenas de fieles que les prestan más atención a los celulares que al orador. Las pesquisas indican que el uso abusivo del celular puede causar depresión y fobia social (Oliveira, 2018, p.75). Siempre según Oliveira (2018), que aborda sobre la nomofobia (uso obsesivo y sin control del smartphone), las personas se quejan de la falta de tiempo, pero pasan muchas horas pegadas al celular, a tal punto de no ser más protagonistas de sus propias vidas y pasan a tener un papel secundario, pues la mayoría del tiempo se preocupan en prestar atención en la vida de los demás como también lo que están haciendo, en lugar de rellenar sus vidas con momentos creados para sí propio. La dependencia digital se compara con los mismos síntomas de la adicción por falta de la droga, o sea, si uno se olvida del celular, se irrita muchísimo. También se observa el estrechamiento de repertorio en el cual la persona se aísla socialmente y no interacciona más con lo social, a parte de los sentimientos de vacío en su interior. Los padres se quejan de la ausencia de los hijos, pues sienten que ellos se distanciaron, a la vez los hijo se sienten próximos de quien está muy lejos de ellos, Aun así, "[...] las amistades digitales no proporcionan los beneficios sicológicos como un contacto frente a frente [...]"(Pinker, 2018, p.328).

Es el distanciamiento emocional, el enfriamiento, la deshumanización de los sentimientos. Scheler (2012, p.182) expone sobre esa "[...] tendencia de desertificar del industrialismo [...]" que representa el decaer del desarrollo de la humanidad, que desemboca también en las cuestiones ecológicas, pues todo se relaciona. Tolledo (2012) destacó que "[...] la contaminación del planeta es apenas un reflejo externo de una contaminación interior psíquica generada por millones de individuos inconscientes sin la menor responsabilidad por los espacios que traen dentro de sí ". Esa reflexión nos remite a los espacios sagrados de las iglesias que no se respetan más, y siendo palcos de muertes. ¿Será que eso también no tiene relación con un sentimiento interior de insignificancia, de la falta de valor, de falta de un sentido de la vida, falta de fe en Dios?, pues si no poseo eso en mi interior, ¿cómo valorizar a los demás?, ¿cómo creer en el mañana?, ¿cómo tener esperanza?

Dürkhein (1996) considera la religión un aspecto esencial y permanente de la humanidad. "Los individuos mueren; las generaciones pasan y son reemplazadas por otras; pero esa fuerza permanece siempre actual. Esta, anima a las generaciones de hoy en día, así como animaba a las de ayer y como animará a las de mañana." (Durkkheim, 1996, p190), y produce efervescencia, que, según Weiss (2013) es lo que añade energía, que estimula, que aumenta el tono vital en el cual el que creyente se siente participando de algo grandioso, fortalecido, nutrido y elevado.

Durkhein (1996) destaca que la efervescencia "[...] nos hace actuar, nos ayuda a vivir ". Por ello, el fiel es un hombre que siempre puede más. Para Aubrée (2013, p.20) la religión no es solamente un sistema de ideas, la misma, es antes de todo, un sistema de fuerzas. Alves (2009, p. 152) escribió sobre el equívoco de Freud: "[...] pensó que la religión era una manifestación de ilusiones que los hombres tienen acerca de su 
propia omnipotencia. Acontece, sin embargo, que si los hombres se juzgaran omnipotentes ellos no tendrían necesidades de evocar a los Dioses.' Neri (2014, p. 301 ) cree que la religiosidad y el soporte social fornecido por la religión, protegen a los ancianos de síntomas de depresión. El diálogo multidisciplinar en las religiones según Teixeira (2008, p. 321) "implica en la apertura y reciprocidad, en el respeto a la especificidad y singularidad de cada uno de los interlocutores." Esto refleja la importancia de los relacionamientos, con Dios y con las personas que nos rodean.

\section{3.-Conclusión.}

La ciencia tiene sus límites, por lo tanto queda clara la impotencia humana delante muchas cosas, principalmente cuando se ve delante de una enfermedad incurable y catástrofes ecológicas. En ese momento, la religión puede ser el MANÀ que los estimule a buscar la cura, la salida, la solidaridad y la solución.

La religión puede representar la fuerza para que no se queden plasmados delante de las dificultades, la esperanza que los hace caminar, el amparo que los estimula a preservar, la sabiduría interior que les permite abrir la mente para nuevas posibilidades y apaciguar el dolor. Pudiendo llevarlos a soñar con días mejores, y transformar el dolor en resiliencia y aprendizaje, para que también puedan ser solidarios con el sufrimiento del prójimo.

Todos sufren pérdidas, y tras las tempestades, el espacio sagrado interior contribuirá para determinar la reacción del individuo, resultando en la respuesta delante del sufrimiento, que pueden surgir valores éticos que uno trae, los que son importantes para poder reconstruirse y levantarse para las caídas.

Humanizar el mundo, trabajar el propio egoísmo, o sea, ¿qué puede hacer uno por sí, por la familia, y por el planeta, para que la ganancia de los hombres no siga contaminando el agua y el aire?

¿Cómo convivir de manera ética en los espacios religiosos, para que el teléfono celular no sea una fuente de desprecio al prójimo?

Escuché a un ciudadano decir en la televisión: ¿¿Qué hay que hacer con la codicia y la vanidad de los políticos que prefieren carteles para que su nombre pueda ser eternizado al contrario de tratar asuntos como saneamiento básico?, pues esto no proporciona visibilidad para el público, pero fornece salud y paz social". Es decir, existen otros modos de cuidar a la gente, y la económica es apenas una de ella. Concientizarse acerca de la fuerza del mundo invisible, a respecto el poder que hace con que "el sol salga todas las mañanas sin nuestro consentimiento" es una manera inteligente de observar el cuidado que la inmensidad del cosmos posee para todos.

Se espera que este estudio pueda contribuir para una nueva mirada sobre el envejecimiento activo, y sobre el importante rol de las religiones como apoyo de la resiliencia en el enfrentamiento de la muerte y de las rupturas en los vínculos existenciales. Observamos sus limitaciones, debido a la falta de datos concretos que puedan demostrar la realidad del anciano delante de un trípode que incluya la 
muerte, la religión y la resiliencia. Pero, vamos a seguir mirando hacia las estrellas... Y creer que el "maná" se acerca.

\section{4.-Referências.}

Arantes. A.C.Q. (2016). A morte é um dia que vale a pena viver. Rio de Janeiro: Casa da Palavra.

Bessa, B. (2018). Recomece. Rio de Janeiro: Sextante.

Varios. (2004). Deuteronômio. In: BÍBLIA. Português. Bíblia de Jerusalém. São Paulo: Paulus.

Bijos, L. (2013). Religião: elo de sustentação do imigrante. In: FREITAS, Marta Helena de; PAIVA Geraldo José de; MORAES, Celia (org.). Psicologia da religião no mundo ocidental contemporâneo: desafios da interdisciplinaridade. Brasília DF: EdUCB.

Cyrulnik, B. (2012). Empezar mal en la vida no determina que tu vida tenga que ser desgraciada. Disponível em:<http://crecejove,com/pedagogia--boriscyrulnik> Acesso em: 24 maio 2019.

Eger, E.E. (2017). The Choice Embrace the possible. New York: Copyright.

Frankl, V.E. (2008). Em busca de sentido: um psicólogo no campo de concentração. 25. ed. Petrópolis: Vozes.

Jung, C.G. (2012). Psicologia e religião. 11. ed. Petrópolis: Vozes.

Taniguchi, J. (2019). O valor do vínculo e da união. In: Revista Seicho-no-ie Mulher Feliz. Mulher Multitarefas. São Paulo: Plural Indústria Gráfica LTDA, p. 7. 